\title{
Interactions of the amphiphiles arbutin and tryptophan with phosphatidylcholine and phosphatidylethanolamine bilayers in the dry state
}

Antoaneta V Popova ${ }^{1,2}$ and Dirk K Hincha ${ }^{1 *}$

\begin{abstract}
Background: Water is essential for life, but some organisms can survive complete desiccation, while many more survive partial dehydration during drying or freezing. The function of some protective molecules, such as sugars, has been extensively studied, but much less is known about the effects of amphiphiles such as flavonoids and other aromatic compounds. Amphiphiles may be largely soluble under fully hydrated conditions, but will partition into membranes upon removal of water. Little is known about the effects of amphiphiles on membrane stability and how amphiphile structure and function are related. Here, we have used two of the most intensively studied amphiphiles, tryptophan (Trp) and arbutin (Arb), along with their isolated hydrophilic moieties glycine (Gly) and glucose (Glc) to better understand structure-function relationships in amphiphile-membrane interactions in the dry state.
\end{abstract}

Results: Fourier-transform infrared (FTIR) spectroscopy was used to measure gel-to-liquid crystalline phase transition temperatures $\left(T_{m}\right)$ of liposomes formed from phosphatidylcholine and phosphatidylethanolamine in the presence of the different additives. In anhydrous samples, both Glc and Arb strongly depressed $T_{m}$, independent of lipid composition, while Gly had no measurable effect. Trp, on the other hand, either depressed or increased $T_{m}$, depending on lipid composition. We found no evidence for strong interactions of any of the compounds with the lipid carbonyl or choline groups, while all additives except Gly seemed to interact with the phosphate groups. In the case of Arb and Glc, this also had a strong effect on the sugar $\mathrm{OH}$ vibrations in the FTIR spectra. In addition, vibrations from the hydrophobic indole and phenol moieties of Trp and Arb, respectively, provided evidence for interactions with the lipid bilayers.

Conclusions: The two amphiphiles Arb and Trp interact differently with dry bilayers. The interactions of Arb are dominated by contributions of the Glc moiety, while the indole governs the effects of Trp. In addition, only Trp-membrane interactions showed a strong influence of lipid composition. Further investigations, using the large structural diversity of plant amphiphiles will help to understand how their structure determines the interaction with membranes and how that influences their biological functions, for example under freezing or dehydration conditions.

Keywords: Amphiphiles, Arbutin, Desiccation, Fourier-transform infrared spectroscopy, Lipid phase transition, Model membranes, Tryptophan

\footnotetext{
* Correspondence: hincha@mpimp-golm.mpg.de

${ }^{1}$ Max-Planck-Institut für Molekulare Pflanzenphysiologie, Am Mühlenberg 1, D-14476 Potsdam, Germany

Full list of author information is available at the end of the article
}

\section{Biomed Central}

(c) 2013 Popova and Hincha; licensee BioMed Central Ltd. This is an Open Access article distributed under the terms of the Creative Commons Attribution License (http://creativecommons.org/licenses/by/2.0), which permits unrestricted use, distribution, and reproduction in any medium, provided the original work is properly cited. 


\section{Background}

While water is generally a pre-requisite of life, some species of microorganisms, plants and invertebrates are able to survive complete desiccation (anhydrobiosis; [1]). Many more species are able to survive partial dehydration, e.g. due to extracellular ice crystallization during freezing. Common and well documented responses to cellular dehydration are increases in the amounts of compatible solutes such as sugars and some amino acids, and the accumulation of stress-protective proteins such as late embryogenesis abundant (LEA) and heat shock proteins (see e.g. [2-4] for reviews).

While the function of these compounds has been widely investigated, the potential function of small amphiphilic molecules in anhydrobiosis and dehydration stress tolerance has received much less attention. Many of these compounds, such as flavonoids, are closely related to plant freezing and drought stress tolerance $[5,6]$, but their function has been mainly discussed in terms of their strong anti-oxidant properties [7]. Amphiphiles are generally found mainly in the aqueous phase of cells under fully hydrated conditions, but reversibly insert into membranes with decreasing water availability [8]. The degree of insertion dependends not only on water availability, but also on the polarity of the substances and potentially on the lipid composition of the target membranes. The interactions may influence membrane stability, but it is so far not possible to predict the effect of a given amphiphile on the stability of a particular membrane $[9,10]$.

In the present study we used two particularly wellinvestigated amphiphiles, tryptophan (Trp) and arbutin (Arb), to elucidate the details of their interactions with membranes upon desiccation and the effects of these interactions on the physical state of the membranes. Arb (4-hydroxyphenyl- $\beta$-D-glucopyranoside) has been found in high concentrations in the leaves of the desiccation tolerant resurrection plant Myrothamnus flabellifolia from South Africa [11,12]. Arb is an antioxidant [13] and inhibits phospholipase $\mathrm{A}_{2}$ in partially dehydrated membranes [14]. It interacts directly with membranes already in the fully hydrated state [15], but membrane stabilization during freezing or drying requires the presence of non-bilayer lipids such as phosphatidylethanolamine (PE) or monogalactosyldiacylglycerol (MGDG) $[16,17]$. In the presence of these lipids, Arb relaxes the inverted curvature stress and thereby stabilizes the bilayer state during dehydration $[10,18]$.

The interactions of the aromatic amino acid Trp with membranes have attracted wide-spread attention, because it is thought to anchor membrane-spanning proteins at the membrane-water interface $[19,20]$. While free Trp shows no measurable interactions with membranes in the fully hydrated state [21], it destabilizes both chloroplast membranes and liposomes during freezing, independent of the lipid composition [22].

Since both the hydrophobic (indole and phenol) and hydrophilic (amino acid and glucose) moieties of Trp and Arb are quite different, distinct interactions with and effects on membranes could be expected. To distinguish the contributions of the hydrophobic and hydrophilic parts of the two molecules, we investigated in addition the effects of glycine (Gly) and glucose (Glc). Fourier-transform infrared (FTIR) spectroscopy was used to monitor the effects of the additives on membranes containing two typical phospholipids, namely the bilayer lipid phosphatidylcholine (PC) and the non-bilayer lipid PE. The analysis of specific vibration bands of the additives provided additional information on their interactions with the lipids and on the role of particular functional groups in the different molecules. A previous detailed investigation of the lipid systems employed in this study has already shown that within the temperature limits employed here (up to $70^{\circ} \mathrm{C}$ ), all membranes are exclusively in a liquid-crystalline bilayer configuration and that no non-bilayer transitions were detectable [23].

\section{Methods}

\section{Liposome preparation}

Egg phosphatidylcholine (EPC), egg phosphatidylethanolamine (EPE) and 1,2 dimyristoyl-sn-glycero-3-phosphocholine (DMPC) were obtained from Avanti Polar Lipids (Alabaster, AL). Trp and Arb were obtained from Fluka, Gly and Glc from Sigma.

Liposomes were made from either pure EPC, pure EPE, or $50 \% \mathrm{EPE} / 50 \% \mathrm{EPC}$ or $50 \% \mathrm{EPE} / 50 \% \mathrm{DMPC}$ on a weight basis. Lipids $(10 \mathrm{mg})$ were dried from the solvent under a gentle steam of $\mathrm{N}_{2}$. Residual chlorophorm was removed under vacuum overnight. The resulting lipid film was hydrated in $200 \mu \mathrm{H} \mathrm{H}_{2} \mathrm{O}$ or in $50 \mathrm{mM}$ solutions of Arb, Trp, Glc or Gly. Large unilamellar liposomes were formed with a hand-held extruder (Avestin, Ottawa, Canada; [24]) with two layers of $100 \mathrm{~nm}$ pore size polycarbonate membranes. Samples $(50 \mu \mathrm{l})$ were spread on $\mathrm{CaF}_{2}$ windows and dried in desiccators over silica gel at $28^{\circ} \mathrm{C}$ for six to eight hours and subsequently kept under vacuum overnight. Since pure EPE does not form bilayers, $2.5 \mathrm{mg}$ lipid in chloroform were spread directly on $\mathrm{CaF}_{2}$ windows, the solvent was evaporated under a stream of $\mathrm{N}_{2}$ and then under vacuum over night [23].

\section{Fourier-transform infrared (FTIR) spectroscopy}

FTIR measurements were performed using a Perkin-Elmer GX 2000 Fourier-transform infrared spectrometer as described previously $[25,26]$. $\mathrm{A} \mathrm{CaF}_{2}$ window with a dry sample was fixed in a cuvette holder placed in a vacuum chamber with a temperature control unit (Specac Eurotherm, Worthington, UK) and placed in the in- 
frared beam. Sample temperature was monitored by a fine thermocouple, attached to the surface of the window, next to the sample. Samples were kept under vacuum for $30 \mathrm{~min}$ at $30^{\circ} \mathrm{C}$ to remove residual water absorbed during handling. The absence of an absorbance band at $1650 \mathrm{~cm}^{-1}$ and the position of the asymmetric $\mathrm{P}=\mathrm{O}$ stretching vibration at $1262 \mathrm{~cm}^{-1}(100 \%$ EPC) indicated that samples were essentially anhydrous $[23,27]$. Temperature was decreased to $-30^{\circ} \mathrm{C}$ and after equilibration for $10 \mathrm{~min}$ the temperature was increased to $70^{\circ} \mathrm{C}$ with a constant rate of $1^{\circ} \mathrm{C} / \mathrm{min}$. Infrared absorbance spectra were recorded between 4000 and $900 \mathrm{~cm}^{-1}$ and analysed using the Spectrum 2000 software (PerkinElmer). The band positions of characteristic molecular group vibrations were analyzed after normalization of absorbance and baseline correction of the spectra by the interactive ABEX and FLAT routines of the software.

Positions of characteristic peaks originating from lipid molecules (compare [27-29]), $\mathrm{CH}_{2}$ symmetric stretching $\left(v \mathrm{CH}_{2} \mathrm{~s}\right), \mathrm{C}=\mathrm{O}$ stretching $(\mathrm{v}=\mathrm{O})$, asymmetric $\mathrm{P}=\mathrm{O}$ stretching $(v \mathrm{P}=$ Oas $)$ and asymmetric choline $\mathrm{N}^{+}\left(\mathrm{CH}_{3}\right)_{3}$ stretching $\left(\mathrm{vN}^{+}\left(\mathrm{CH}_{3}\right)_{3}\right.$ as) vibrations were determined by the automatic peak identification routine. Hydrogen bonding interactions of the $\mathrm{OH}$ groups of Glc and Arb were analyzed through the broad peak of the $\mathrm{OH}$ stretching band $(\mathrm{vOH})$ in the spectral region of $3600-$ $3000 \mathrm{~cm}^{-1}$ [30]. The vibration peaks arising from the indole part of Trp $\left(3430-3380 \mathrm{~cm}^{-1}\right)$, from the amino part of Trp and Gly $\left(1690-1550 \mathrm{~cm}^{-1}\right)$ and from the phenol group of Arb $\left(1530-1490 \mathrm{~cm}^{-1}\right)$ were also used to determine interactions between lipids and additives. Except for the $v \mathrm{CH}_{2} \mathrm{~S}$ vibration, all peaks were analysed at $70^{\circ} \mathrm{C}$ where all lipid membranes were in the liquidcrystalline phase (compare Table 1). The gel to liquidcrystalline phase transition temperatures $\left(\mathrm{T}_{\mathrm{m}}\right)$ of the lipids in the absence and presence of additives were determined as the midpoints of the lipid melting curves monitored as the temperature dependent increase in the

Table $1 \mathrm{Gel}$ to liquid-crystalline phase transition temperatures $\left(T_{m}\right.$ in $\left.{ }^{\circ} \mathrm{C}\right)$ of dry liposomes in the absence (pure) or presence of Arb, Glc, Trp, or Gly

\begin{tabular}{cccccc}
\hline Lipid composition & Pure & Arb & Glc & Trp & Gly \\
\hline $\mathbf{1 0 0 \%}$ EPC & 40 & -24 & -24 & 20 & 40 \\
$\mathbf{1 0 0 \%}$ EPE & -3 & -18 & -18 & 5 & -2 \\
$\mathbf{5 0 \%}$ EPE/ & 0 & -22 & -15 & 20 & 2 \\
$\mathbf{5 0 \%}$ EPC & & & & & \\
$\mathbf{5 0 \%}$ EPE/ & 48 & -20 & -13 & 29 & 51 \\
$\mathbf{5 0 \% ~ D M P C}$ & & & & & \\
\hline
\end{tabular}

$T_{m}$ was determined by FTIR spectroscopy as the midpoint of melting curves obtained as shown in Figure 1. Data for the pure lipids are identical to those published previously [23]. position of the $\mathrm{vCH}_{2} \mathrm{~S}$ peak [29]. Interactions at the level of $\mathrm{C}=\mathrm{O}$ esters were estimated by analyzing the $\mathrm{vC}=\mathrm{O}$ stretching peak by deconvolution using Origin7.0 [27,31].

\section{Results}

\section{Membrane phase behavior}

The physical state of lipid bilayers can be monitored by the temperature-induced shift of the $\mathrm{vCH}_{2} \mathrm{~S}$ peak to higher wavenumbers, as this vibration is sensitive to changes in the conformational disorder of the hydrocarbon chains [29]. The midpoint of this transition is defined as the gel to liquid-crystalline phase transition temperature $\left(\mathrm{T}_{\mathrm{m}}\right)$. Figure 1 shows the effects of the additives Arb, Glc, Trp and Gly on the melting curves of EPC liposomes after drying. Dry EPC showed a $T_{m}$ of $40^{\circ} \mathrm{C}$ (Table 1), while the addition of either Arb or Glc depressed $\mathrm{T}_{\mathrm{m}}$ by more than $60^{\circ} \mathrm{C}$ to $-24^{\circ} \mathrm{C}$. In the presence of $\operatorname{Trp}$ the $\mathrm{T}_{\mathrm{m}}$ of EPC was decreased more moderately by $20^{\circ} \mathrm{C}$, while Gly had no measurable influence. Phase transition temperatures for all other lipids (pure EPE, 50\% EPE/50\% EPC, 50\% EPE/50\% DMPC) in the absence and presence of all additives are presented in Table 1. Arb and Glc caused a large depression of $\mathrm{T}_{\mathrm{m}}$ for all investigated lipids. This ranged from $15-20^{\circ} \mathrm{C}$ for $\mathrm{EPE}$ and EPE/EPC membranes to $60-70^{\circ} \mathrm{C}$ for EPE/DMPC. The effects of $\operatorname{Trp}$ on $\mathrm{T}_{\mathrm{m}}$ were generally smaller $\left(10-20^{\circ} \mathrm{C}\right)$, with increases for EPE and EPE/EPC and decreases for EPC and EPE/DMPC. Gly, on the other hand, did not influence the $\mathrm{T}_{\mathrm{m}}$ of any of these lipids.

The destabilizing effect of Trp on model membranes and in particular the induction of vesicle fusion during freezing, has been suggested earlier to be partially due to the formation of hexagonal $\left(\mathrm{H}_{\mathrm{II}}\right)$ phase [22]. DSC

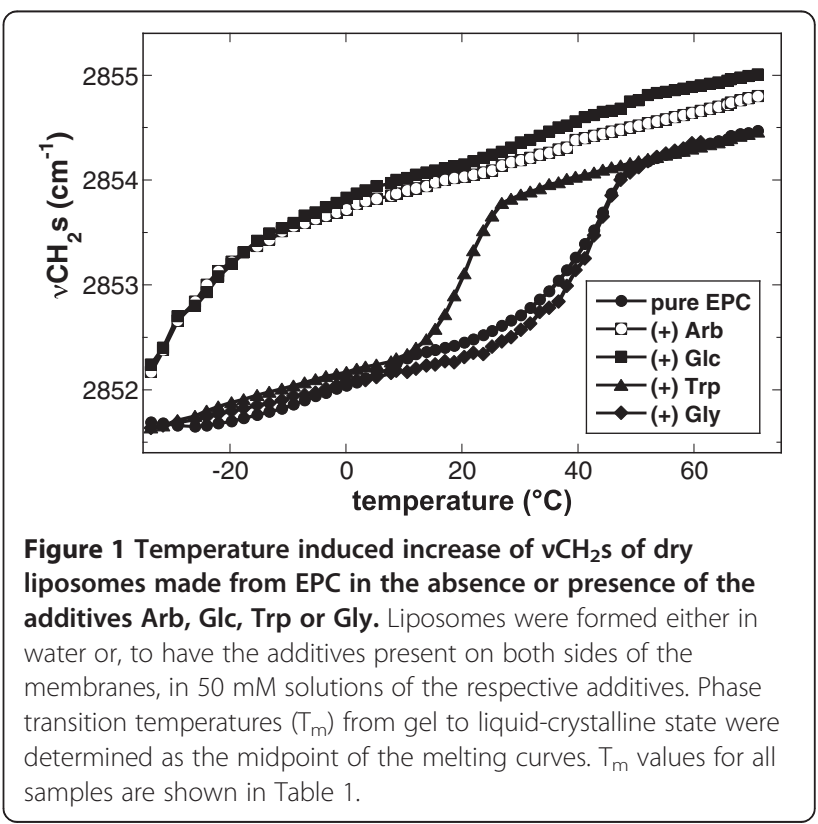


measurements, however, provided no evidence for Trpinduced formation of $\mathrm{H}_{\mathrm{II}}$ in any of the investigated membrane systems in the dry state (data not shown).

\section{Interactions in the interfacial headgroup region}

Since the effects of the additives on lipid phase transitions varied widely both between additives and lipids, it was of interest to investigate possible solute-lipid interactions in more detail.

The carbonyl ester groups $(\mathrm{C}=\mathrm{O})$ of diacyl lipids are situated between the hydrophobic fatty acyl chains and the hydrophilic headgroup region. In the dry state, they are potential $\mathrm{H}$-bonding partners for the headgroups of neighbouring lipid molecules and for any additives. The $\mathrm{C}=\mathrm{O}$ groups give rise to an infrared vibration peak centered at around $1738 \mathrm{~cm}^{-1}$. As described in detail in a previous publication [23], the $\mathrm{C}=\mathrm{O}$ peak position varied by several wavenumbers with lipid composition (Figure 2). However, the different additives had no influence on the peak position. Nevertheless, in EPE both Arb and Trp induced a peak broadening towards the low-wavenumber side, indicating a low degree of interaction with the $\mathrm{C}=\mathrm{O}$ groups. This was also observed for EPE/EPC and EPE/DMPC liposomes (data not shown), but not for pure EPC (Figure 2). Glc only had a very small effect, while spectra recorded in the presence of Gly were in all cases identical to those obtained with the pure lipids.

The $\mathrm{C}=\mathrm{O}$ peak is composed of two component bands arising from free and $\mathrm{H}$-bonded $\mathrm{C}=\mathrm{O}$ groups. The higher wavenumber component at about $1742 \mathrm{~cm}^{-1}$ is attributed to non-H-bonded (free) $\mathrm{C}=\mathrm{O}$ groups, while the lower wavenumber component at about $1726 \mathrm{~cm}^{-1}$ originates from $\mathrm{H}$-bonded $\mathrm{C}=\mathrm{O}$ groups [32-34]. The ratio between the areas under the two component peaks is proportional to the relative fraction of $\mathrm{C}=\mathrm{O}$ groups involved in H-bonding [27,31]. However, deconvolution of the $\mathrm{C}=\mathrm{O}$ peaks revealed the expected differences between the different lipid compositions [23], but only minor effects of the additives (data not shown), again indication only a low degree of interactions.

The hydrophilic headgroups of the phospholipids in this study contain the phosphate $(\mathrm{P}=\mathrm{O})$, and choline $\left(\mathrm{N}^{+}\left(\mathrm{CH}_{3}\right)_{3}\right)$ or ethanolamine $\left(\mathrm{N}^{+} \mathrm{CH}_{3}\right)$ moieties. The $\mathrm{P}=\mathrm{O}$ group is characterized by an infrared asymmetric vibration peak between 1300 and $1200 \mathrm{~cm}^{-1}$. This peak is located at about $1260 \mathrm{~cm}^{-1}$ for anhydrous PC and can shift to around $1220 \mathrm{~cm}^{-1}$ depending on the extent of $\mathrm{H}$-bonding to e.g. water or sugars $[28,34,35]$. Figure 3 shows the positions of $v \mathrm{P}=$ Oas from the different lipids in the absence and presence of Trp, Gly or Glc. Unfortunately, the effect of Arb on $v \mathrm{P}=$ Oas could not be investigated due to overlap with a prominent peak originating from the phenol part of Arb $\left(1260-1170 \mathrm{~cm}^{-1}\right)$.

For all lipids in the absence of additives the $v \mathrm{P}=$ Oas peak was situated between $1261 \mathrm{~cm}^{-1}$ for EPC and $1230 \mathrm{~cm}^{-1}$ for EPE, in agreement with previous publications $[23,36]$. In the presence of Trp the $\mathrm{P}=\mathrm{O}$ peak of pure EPC was shifted from $1261 \mathrm{~cm}^{-1}$ to $1246 \mathrm{~cm}^{-1}$, indicating that Trp was $\mathrm{H}$-bonded to the $\mathrm{P}=\mathrm{O}$ groups of the lipid. Addition of Gly to EPC liposomes, on the other hand, had no clear influence on $v \mathrm{P}=$ Oas (peak shift of less than $2 \mathrm{~cm}^{-1}$ ). Such a slight shift or no shift in the peak position was also observed for the other lipids, indicating only a very low level of $\mathrm{H}$-bonding between $\mathrm{P}=\mathrm{O}$ groups and Gly even in the dry state. The largest shift by $24 \mathrm{~cm}^{-1}$ was observed in $v \mathrm{P}=$ Oas of EPC in the presence of Glc. This position was $8 \mathrm{~cm}^{-1}$ lower than in the presence of Trp, indicating that the $\mathrm{P}=\mathrm{O}$ groups were involved in more $\mathrm{H}$-bonding interactions, in agreement with the general propensity of sugars to $\mathrm{H}$-bond to anhydrous lipids [35,37].

For EPE and EPE/EPC all investigated additives had no or only a very sligh effect on $v \mathrm{P}=$ Oas. The

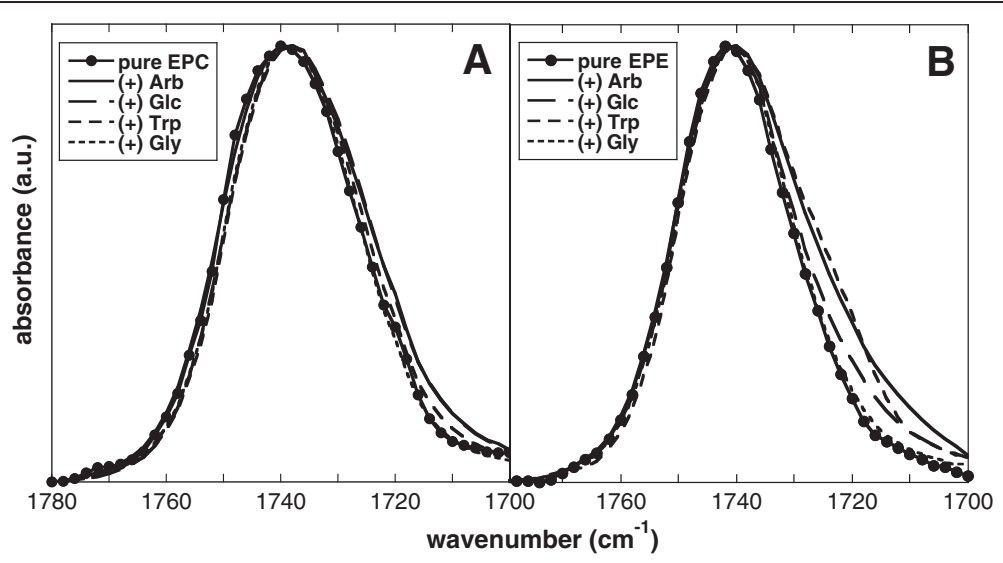

Figure 2 Normalized infrared peaks of the $\mathbf{v C}=\mathbf{O}$ vibration from dry bilayers. EPC (A) and EPE (B) liposomes were dried in the absence or presence of Arb, Glc, Trp or Gly and FTIR spectra were obtained at $70^{\circ} \mathrm{C}$. 


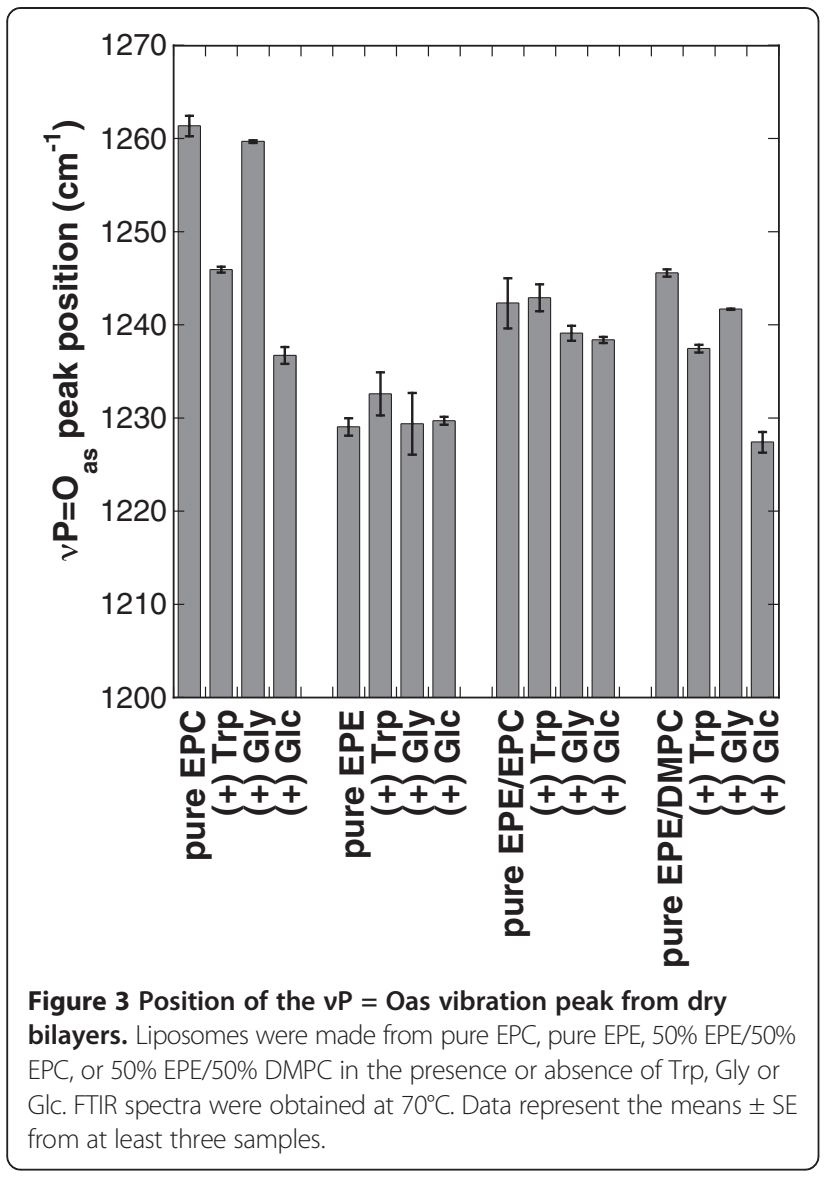

maximum effect for EPE/EPC was about $4.5 \mathrm{~cm}^{-1}$ and for EPE about $3 \mathrm{~cm}^{-1}$, indicating that the $\mathrm{P}=\mathrm{O}$ groups preferentially interacted with ethanolamine groups rather than with the additives [23,36]. Stronger effects of Trp and Glc on $v \mathrm{P}=$ Oas were found for EPE/DMPC. Here, $v \mathrm{P}=$ Oas was shifted by $8 \mathrm{~cm}^{-1}$ with Trp and by $18 \mathrm{~cm}^{-1}$ with Glc.

The terminal part of the PC headgroup is the choline moiety that gives rise to an asymmetric stretching vibration at around $970 \mathrm{~cm}^{-1}$, that is sensitive to H-bonding interactions with water $[26,38]$ or sugars $[27,39]$. When the choline group is involved in such interactions, its vibration is shifted by a maximum of $4 \mathrm{~cm}^{-1}$ to higher wavenumbers $[27,39]$. Here, we generally observed shifts in $v \mathrm{~N}^{+}\left(\mathrm{CH}_{3}\right)_{3}$ as of less than $1 \mathrm{~cm}^{-1}$ (data not shown), indicating that the additives only weakly interact with the choline group.

Interactions between lipids and additives as revealed by IR peaks derived from the additives

An important advantage of infrared spectroscopy is that every chemical group in a sample gives rise to specific vibrations, providing simultaneous information on different components of a mixture. The substances investigated in the present study are all characterized by typical peaks in the FTIR spectra that allowed the evaluation of interactions between additives and membrane lipids.
The phenol moiety of Arb is characterized by two peaks in the IR regions of $1260-1170 \mathrm{~cm}^{-1}$ and $1530-1490 \mathrm{~cm}^{-1}$. As mentioned above, the lower wavenumber peak overlaps with $v \mathrm{P}=$ Oas of phospholipids and was therefore not suitable for the evaluation of phospholipid-Arb interactions. The second peak, originating from the vibration of aromatic double bonds, was centered at about $1510 \mathrm{~cm}^{-1}$ for dry Arb in the absence and presence of liposomes (Figure 4), in agreement with published data [40]. The presence of liposomes, however, resulted in peak narrowing. Peak width at half-height was reduced from $17 \mathrm{~cm}^{-1}$ for pure Arb to $12.5 \mathrm{~cm}^{-1}$ in the presence of EPC, $14 \mathrm{~cm}^{-1}$ with EPE and $\mathrm{EPE} / \mathrm{EPC}$, and $10.5 \mathrm{~cm}^{-1}$ with EPE/DMPC, indicating a more restricted range of vibrations in the presence of lipid, in agreement with the proposed localization of the phenol moiety of Arb in the membranes [15].

Interactions between Glc, either in the free form or as a part of the Arb molecule, and membrane lipids was monitored through the $\mathrm{OH}$ stretching vibration $(\mathrm{vOH})$ between 3600 and $3000 \mathrm{~cm}^{-1}$. The position of $\mathrm{vOH}$ provides information about the length and strength of $\mathrm{H}$-bonds formed by $\mathrm{OH}$ groups of Glc [30], with peaks at lower wavenumbers indicating shorter and stronger $\mathrm{H}$-bonds. The $\mathrm{vOH}$ peak of dry Glc was situated at $3368 \mathrm{~cm}^{-1}$ (Figure 5), in good agreement with a published value of $3360 \mathrm{~cm}^{-1}$ [41]. The $\mathrm{vOH}$ peak of dry Arb was located at $3372 \mathrm{~cm}^{-1}$, indicating a similar physical environment for Glc in both cases. The presence of liposomes shifted the peak downfield by around $100 \mathrm{~cm}^{-1}$

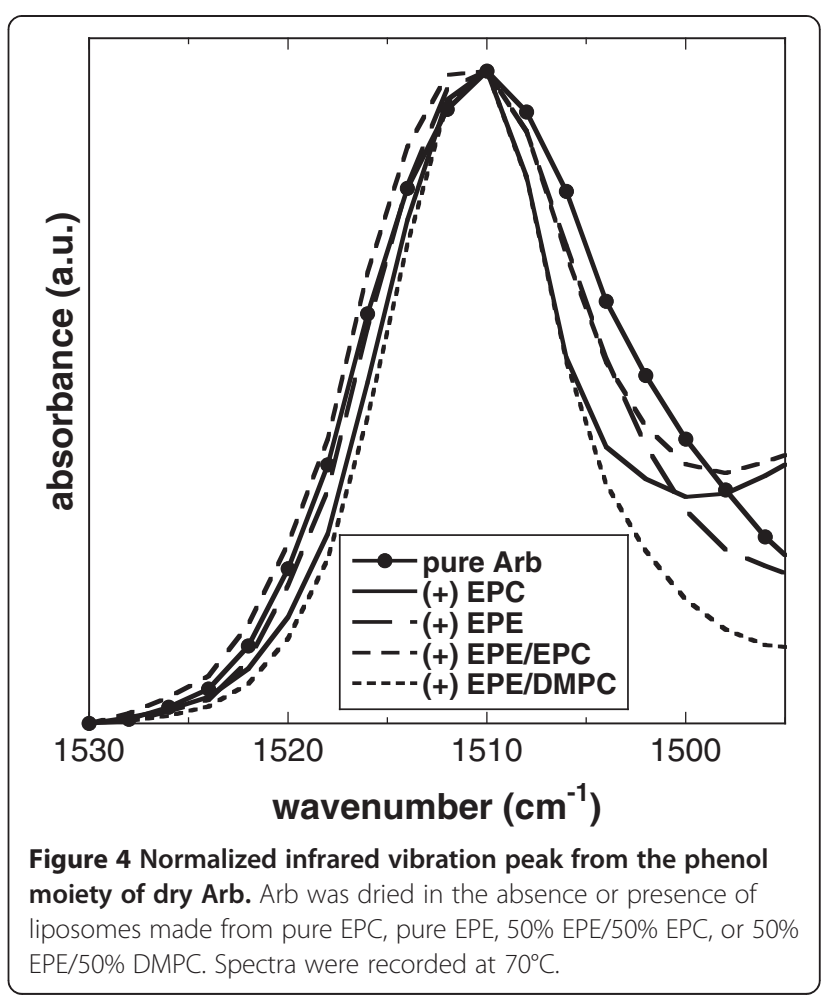




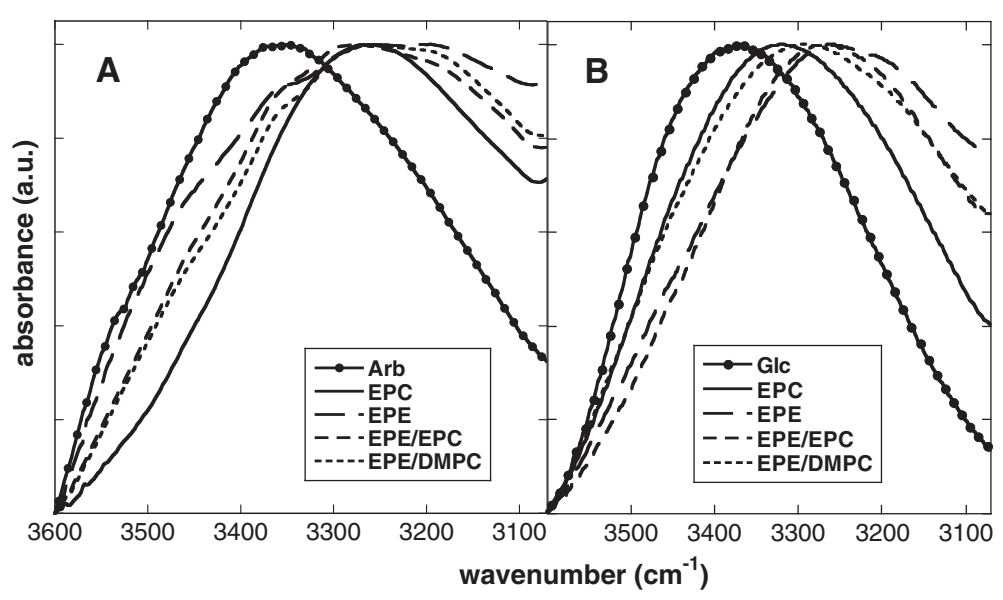

Figure 5 Normalized $v \mathrm{OH}$ peaks originating from $\mathrm{OH}$ groups of the Glc moiety of dry Arb (A) or of free Glc (B). The solutes were dried in the absence or presence of liposomes made from pure EPC, pure EPE, 50\% EPE $/ 50 \% \mathrm{EPC}$, or $50 \% \mathrm{EPE} / 50 \% \mathrm{DMPC}$. Spectra were recorded at $70^{\circ} \mathrm{C}$.

indicating a strong H-bonding network between Glc and the membrane lipids both for free Glc and for the Glc in Arb. The similar positions of $\mathrm{vOH}$ in both cases indicate H-bonding networks of similar strengths.

The aromatic amino acid Trp shows two characteristic absorbance peaks in the FTIR spectrum. A peak between 3430 and $3380 \mathrm{~cm}^{-1}$ is attributed to vibrations from the indole part of the molecule $[42,43]$ and a double peak, originating from the amino part, in the region between 1690 and $1550 \mathrm{~cm}^{-1}$ is also found in the Gly spectrum. The indole peak of pure dry Trp was located at $3402 \mathrm{~cm}^{-1}$ (Figure 6). In the presence of liposomes this peak was shifted to $3406 \mathrm{~cm}^{-1}$, irrespective of the lipid composition. In the presence of pure EPC or EPE liposomes there was a clear shoulder at about $3396 \mathrm{~cm}^{-1}$, which was hardly visible in the mixed membranes.

The two peaks originating from the amino groups of the amino acids were located at 1668 and $1590 \mathrm{~cm}^{-1}$ in the case of Trp and at 1662 and $1614 \mathrm{~cm}^{-1}$ for Gly (Figure 7). In the presence of liposomes both Trp maxima were shifted, the high-wavenumber peak by $2 \mathrm{~cm}^{-1}$ and the low-wavenumber peak between $4 \mathrm{~cm}^{-1}$ for pure EPE and $12 \mathrm{~cm}^{-1}$ for pure EPC. The high-wavenumber peak of Gly was relatively smaller than the corresponding Trp peak and was not consistently influenced by the presence of lipids. The low-wavenumber peak of Gly, on the other hand, showed a significant narrowing in the presence of all lipids and a shift to lower wavenumbers in the presence of EPE (pure EPE by $10 \mathrm{~cm}^{-1}, \mathrm{EPE} / \mathrm{EPC}$ by $4 \mathrm{~cm}^{-1}$, EPE/DMPC by $\left.2 \mathrm{~cm}^{-1}\right)$.

\section{Discussion}

The effect of Arb on dry bilayers is dominated by Glc-lipid interactions

Sugars can preserve the structural and functional integrity of membranes in the anhydrous state [35,37]. This has been extensively investigated with disaccharides such as sucrose and trehalose. However, also monosaccharides such as Glc are able to depress the $\mathrm{T}_{\mathrm{m}}$ of PC in the dry state [44]. The $\mathrm{T}_{\mathrm{m}}$ of dry $\mathrm{EPC}$ is $40^{\circ} \mathrm{C}[26,44]$ and it was depressed to $-24^{\circ} \mathrm{C}$ by both Arb and Glc, while for EPE it was shifted from about $0^{\circ} \mathrm{C}$ [44] to $-18^{\circ} \mathrm{C}$ by both additives. A depression of $\mathrm{T}_{\mathrm{m}}$ in dry PC by Arb has been reported previously [15]. Interestingly, the $\mathrm{T}_{\mathrm{m}}$ of both EPE/EPC and EPE/DMPC was about $7^{\circ} \mathrm{C}$ lower in the presence of Arb than Glc, indicating that Glc fixed to the membrane

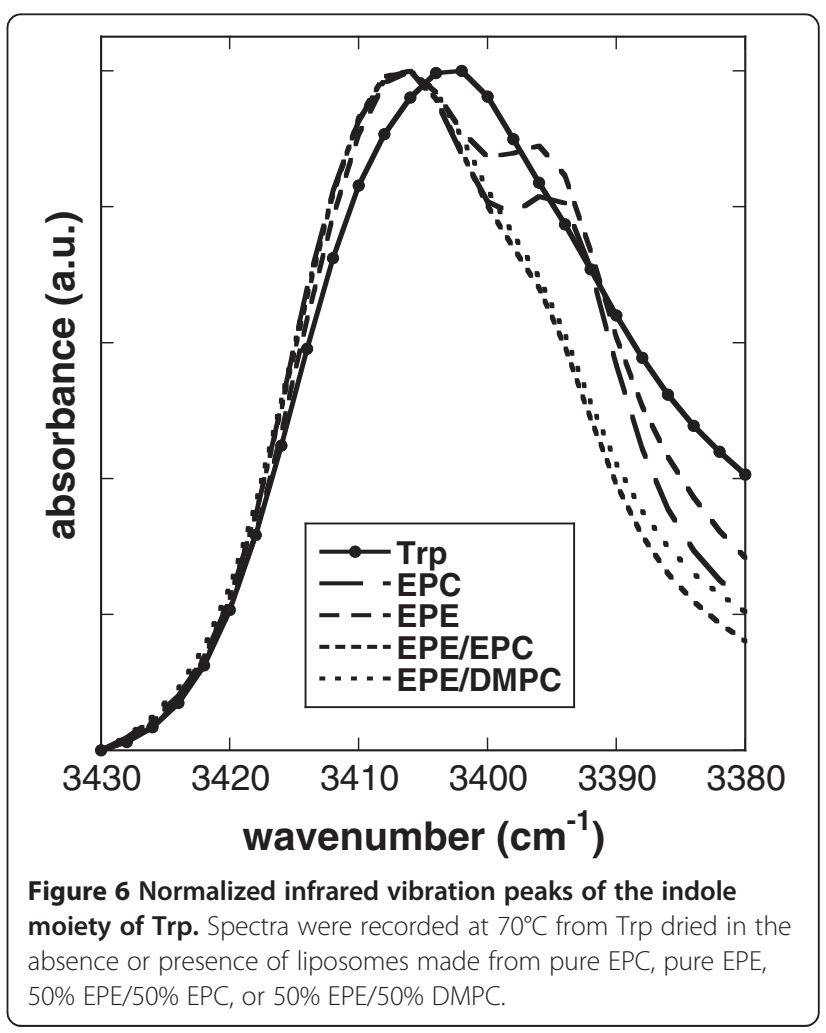




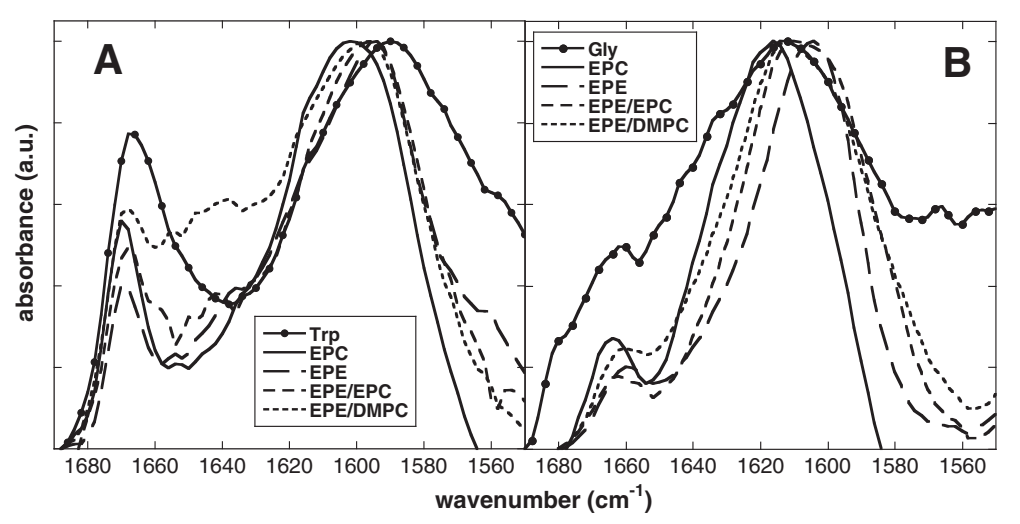

Figure 7 Normalized infrared vibration peaks of the amino groups of dry $\operatorname{Trp}$ (A) or Gly (B). The amino acids were dried in the absence or presence of liposomes made from pure EPC, pure EPE, 50\% EPE/50\% EPC, or 50\% EPE/50\% DMPC. Spectra were recorded at $70^{\circ} \mathrm{C}$.

surface by the phenol moiety of Arb may under some conditions be more effective than free Glc. A similar conclusion was reached for free and lipid-bound di-galactose in a previous study [45].

The decrease of $\mathrm{T}_{\mathrm{m}}$ of dry lipids in the presence of sugars is related to the ability of sugars to $\mathrm{H}$-bond with their $\mathrm{OH}$ groups to the $\mathrm{P}=\mathrm{O}$ headgroups of phospholipids, as demonstrated by a shift of $v \mathrm{P}=$ Oas to lower wavenumbers (see e.g. [35,37] for comprehensive reviews). Here, we showed a down-shift of $v \mathrm{P}=$ Oas of dry EPC by $24 \mathrm{~cm}^{-1}$ in the presence of Glc. Unfortunately, $v \mathrm{P}=$ Oas does not provide information about $\mathrm{H}$ bonding interactions between Arb and lipid $\mathrm{P}=\mathrm{O}$ groups due to the overlap with the peak originating from the phenol moiety of Arb. However, indirect information about such interactions can be gained from the analysis of the $\nu \mathrm{OH}$ vibrations of Arb and Glc. The $v \mathrm{OH}$ peaks from both substances showed the same massive downshift by about $100 \mathrm{~cm}^{-1}$ in the presence of liposomes, indicating that Arb depressed $\mathrm{T}_{\mathrm{m}}$ by the same mechanism as free Glc, i.e. by $\mathrm{H}$-bonding of $\mathrm{Glc} \mathrm{OH}$ groups to the $\mathrm{P}=\mathrm{O}$ groups of the lipids.

For EPE liposomes, the position of the $\mathrm{P}=\mathrm{O}$ peak is only slightly affected by the presence of Glc, which could indicate the absence of $\mathrm{H}$-bonding interactions. However, we note that the position of $v \mathrm{P}=$ Oas for anhydrous EPE (1230-1234 $\left.\mathrm{cm}^{-1}\right)[23,46]$ is also only shifted by about $15 \mathrm{~cm}^{-1}$ from the fully hydrated state $[47,48]$, while the shift is about $40 \mathrm{~cm}^{-1}$ for PC [34]. This indicates that even in the presence of excess water $\mathrm{P}=\mathrm{O}$ groups of PE preferentially interact with the lipid ethanolamine groups. These strong interactions persist also in mixed PE/PC liposomes [23]. In all cases, the ethanolamine headgroups of $\mathrm{PE}$ are involved in a tight $\mathrm{H}$-bonding network with the $\mathrm{P}=\mathrm{O}$ groups of phospholipids [49].

The present data suggest that when Glc is added to fully hydrated liposomes, $\mathrm{OH}$ groups of Glc compete with ethanolamine groups for $\mathrm{H}$-bonding to $\mathrm{P}=\mathrm{O}$ groups upon the removal of water. We cannot evaluate to what extent $\mathrm{P}=\mathrm{O}$ groups are involved in $\mathrm{H}$-bonds with either ethanolamine or Glc, but it is reasonable to assume that $\mathrm{P}=\mathrm{O}$ groups will preferentially be $\mathrm{H}$-bonded with $\mathrm{OH}$ groups of Glc rather than with ethanolamine groups as $\mathrm{O}-\mathrm{H} \cdots \mathrm{O}$ bonds are stronger than $\mathrm{C}-\mathrm{H} \ldots \mathrm{O}$ bonds [30].

In addition to the Glc, also the phenol part of Arb interacts with lipid bilayers, as shown by fluorescence spectroscopy with hydrated membranes [15] and by the narrowing of the corresponding FTIR peak in the dry state reported here. While the interaction with Arbbound Glc has the same effect on $\mathrm{T}_{\mathrm{m}}$ of both bilayer and non-bilayer forming lipids, the effects on liposome stability measured as carboxy fluorescein (CF) leakage or membrane fusion, are different. While liposomes made from PC are strongly destabilized during freezing or drying, the inclusion of non-bilayer lipids such as $\mathrm{PE}$ or MGDG results in membrane stabilization by Arb [15-17]. It has been argued that Arb destabilizes membranes containing only bilayer lipids due to the partitioning of its phenol moiety into the membrane-water interface, thus eliciting positive membrane curvature stress. On the other hand, when membranes contain non-bilayer lipids, these cone-shaped molecules [50] induce negative curvature stress that will be further increased on removing water [51]. In this case, the insertion of Arb into the membrane interface reduces the negative curvature stress and stabilizes the lipids in a bilayer configuration $[16,17]$.

The effect of Trp on dry bilayers is dominated by indolelipid interactions

Trp decreased $\mathrm{T}_{\mathrm{m}}$ for EPC and EPE/DMPC liposomes, while for EPE and EPE/EPC the transition from gel to liquid-crystalline phase occurred at temperatures higher than for the pure lipid bilayers. Interestingly, the influence of Trp on liposome stability, measured as either CF leakage or membrane fusion, was independent of lipid composition. Trp destabilized membranes made from 
pure EPC and from EPE/EPC, although the effect was more pronounced for membranes containing EPE [22]. Gly, on the other hand, had no measurable influence on $\mathrm{T}_{\mathrm{m}}$, regardless of lipid composition, in agreement with our earlier data for EPC [42]. This indicates that unlike the Glc in Arb, the hydrophilic amino acid part of Trp plays no important role in Trp-membrane interactions in the dry state. This is in agreement with the fact that the vibration peak attributed to the amino part of Trp and Gly was not changed in its position in the presence of membranes. However, in the presence of liposomes this peak was more cooperative than for the pure substances, indicating restricted vibration. In addition, the presence of Gly induced only a small shift in $v \mathrm{P}=$ Oas, in agreement with only minor interactions.

The shift in $v \mathrm{P}=$ Oas induced by Trp in EPC was considerably larger, but we suggest that it was not due to interactions with the amino acid moiety. It has been shown both experimentally and in Molecular Dynamics (MD) simulations that indole or Trp in small peptides localize mainly in the interfacial region between the first two to three carbons of the hydrocarbon chains and the choline group in fully hydrated PC membranes [52-58]. In agreement with our data, earlier studies indicate the possibility of interactions between the indole $\mathrm{NH}$ group and lipid $\mathrm{P}=\mathrm{O}$, while interactions with the lipid $\mathrm{C}=\mathrm{O}$ groups are of minor importance $[52,55,56,58]$.

Analogous to what we have discussed above for Glc and Arb, we suggest that also the interactions between Trp and EPE involve $\mathrm{H}$-bonding to $\mathrm{P}=\mathrm{O}$ groups, although the position of the $v \mathrm{P}=$ Oas peak is not strongly influenced. Again, this may be explained by competition of the indole $\mathrm{NH}$ groups with ethanolamine groups for bonding to $\mathrm{P}=\mathrm{O}$ groups. This is supported by a shift of the peak attributed to the Trp indole ring by about $4 \mathrm{~cm}^{-1}$ in the presence of liposomes, independent of lipid composition, indicating similar interactions with EPC and EPE. This is in agreement with MD simulations that found similar interactions of Trp in gramicidin A with either PE or PC bilayers [57].

One of the most striking effects that we observed in this study is the opposite direction of changes in $T_{m}$ in the presence of Trp, depending on lipid composition. While $\mathrm{T}_{\mathrm{m}}$ was decreased for dry EPC and EPE/DMPC by $20^{\circ} \mathrm{C}$, it was increased by $8^{\circ} \mathrm{C}$ and $20^{\circ} \mathrm{C}$ for EPE and EPE/EPC, respectively. The decrease of $T_{m}$ in EPC membranes by Trp can be easily explained on the basis of published data. Both experimental and MD studies have shown that the indole ring is fairly rigid and oriented parallel to the fatty acyl chains in lipid bilayers $[52,53,55,58]$. The localization of the indole ring near the glycerol backbone leads to interactions with the upper part of the fatty acyl chains, reducing molecular mobility in this part of the lipid molecules. At the same time, this results in a wider spacing of the lipids and increased space and mobility in the lower parts of the chains that can be observed as a decrease in $\mathrm{T}_{\mathrm{m}}$ in our FTIR experiments. Unfortunately, there are no comparative data or simulations for PE lipids in the literature. However, it can be reasonably speculated that the cone shaped PE molecules will allow a deeper penetration of the indole ring into the fatty acyl chain region of the bilayers due to the formation of geometrical defects, as recently characterized in an MD simulation study [59]. This could limit chain mobility sufficiently to increase $T_{m}$, while the effect of EPE could be counterbalanced by DMPC. The fully saturated fatty acyl chains may lead to stronger interactions of the rigid indole ring with this lipid [52] than with EPE, again inducing higher mobility in the lower chain region. However, this hypothesis needs to be tested in future experiments and MD simulations.

\section{Conclusions}

In conclusion, we have shown in this study that the two amphiphiles Arb and Trp have different modes of interaction with dry bilayers. While the interactions of Arb are completely dominated by the contribution of the hydrophilic Glc moiety, the hydrophobic indole determines the effects of Trp. In addition, there was only a small effect of lipid composition on Arb-bilayer interactions, while a pronounced influence of lipid composition was obvious for Trp-membrane interactions. Further investigations, that could e.g. use the large structural diversity of flavonoids, which are also known to efficiently interact with lipid bilayers [60-63], will be needed to understand how amphiphile structure determines the interaction with membranes. In addition, such investigations could shed light on the functional relevance of the large natural diversity in the structure of these molecules and relate it to biological functions, such as plant freezing and dehydration tolerance.

\section{Competing interests}

The authors declare that they have no competing interests.

\section{Authors' contributions}

AVP designed and conducted all experiments, analyzed the data and drafted the manuscript. DKH participated in experimental design and data analysis, and wrote the final manuscript. Both authors read and approved the final manuscript.

\section{Author details}

${ }^{1}$ Max-Planck-Institut für Molekulare Pflanzenphysiologie, Am Mühlenberg 1, D-14476 Potsdam, Germany. ${ }^{2}$ Institute of Biophysics and Biomedical Engineering, Bulgarian Academy of Sciences, 1113 Sofia, Bulgaria.

Received: 22 February 2013 Accepted: 17 April 2013

Published: 24 July 2013

\section{References}

1. Crowe JH, Hoekstra FA, Crowe LM: Anhydrobiosis. Annu Rev Physiol 1992, 54:579-599. 
2. Hand SC, Menze MA, Toner M, Boswell L, Moore D: LEA proteins during water stress: not just for plants anymore. Annu Rev Physiol 2011, 73:1 15-134.

3. Tunnacliffe A, Hincha DK, Leprince O, Macherel D: LEA proteins: versatility of form and function. In Sleeping beauties - dormancy and resistance in harsh environments. Edited by Lubzens E, Cerda J, Clark M. Berlin: Springer; 2010:91-108.

4. Tunnacliffe A, Wise MJ: The continuing conundrum of LEA proteins. Naturwissenschaften 2007, 94:791-812.

5. Korn M, Peterek S, Mock H-P, Heyer AG, Hincha DK: Heterosis in the freezing tolerance, and sugar and flavonoid contents of crosses between Arabidopsis thaliana accessions of widely varying freezing tolerance. Plant Cell Environ 2008, 31:813-827.

6. Winkel-Shirley B: Biosynthesis of flavonoids and effects of stress. Curr Opin Plant Biol 2002, 5:218-223.

7. Rice-Evans CA, Miller NJ, Paganga G: Antioxidant properties of phenolic compounds. Trends Plant Sci 1997, 2:152-159.

8. Golovina EA, Hoekstra FA, Hemminga MA: Drying increases intracellular partitioning of amphiphilic substances into the lipid phase. Plant Physiol 1998, 118:975-986

9. Golovina EA, Hoekstra FA: Membrane behavior as influenced by partitioning of amphiphiles during drying: a comparative study in anhydrobiotic plant systems. Comp Biochem Physiol 2002, 131A:545-558.

10. Oliver AE, Leprince O, Wolkers WF, Hincha DK, Heyer AG, Crowe JH: Non-disaccharide-based mechanisms of protection during drying. Cryobiology 2001, 43:151-167.

11. Bianchi G, Gamba A, Limiroli R, Pozzi N, Elster R, Salamini F, Bartels D: The unusual sugar composition in leaves of the resurrection plant Myrothamnus flabellifolia. Physiol Plant 1993, 87:223-226.

12. Suau R, Cuevas A, Valpuesta V, Reid MS: Arbutin and sucrose in the leaves of the resurrection plant Myrothamnus labellifolia. Phytochemistry 1991, 30:2555-2556.

13. loku K, Terao J, Nakatani N: Antioxidative activity of arbutin in a solution and liposomal suspension. Biosci Biotech Biochem 1992, 56:1658-1659.

14. Oliver AE, Crowe LM, de Araujo PS, Fisk E, Crowe JH: Arbutin inhibits PLA in partially hydrated model systems. Biochim Biophys Acta 1996, 1302:69-78.

15. Oliver AE, Hincha DK, Crowe LM, Crowe JH: Interactions of arbutin with dry and hydrated bilayers. Biochim Biophys Acta 1998, 1370:87-97.

16. Hincha DK, Oliver AE, Crowe JH: Lipid composition determines the effects of arbutin on the stability of membranes. Biophys J 1999, 77:2024-2034.

17. Oliver AE, Hincha DK, Tsvetkova NM, Vigh L, Crowe JH: The effect of arbutin on membrane integrity during drying is mediated by stabilization of the lamellar phase in the presence of nonbilayer-forming lipids. Chem Phys Lipids 2001, 111:37-57.

18. Oliver AE, Hincha DK, Crowe JH: Looking beyond sugars: the role of amphiphilic solutes in preventing adventitious reactions in anhydrobiotes at low water contents. Comp Biochem Physiol 2002, 131A:515-525.

19. Landolt-Marticorena C, Williams KA, Deber CM, Reithmeier RAF: Non-random distribution of amino acids in the transmembrane segments of human type I single span membrane proteins. J Mol Biol 1993, 229:602-608.

20. Ulmschneider MB, Sansom MSP: Amino acid distributions in integral membrane protein structures. Biochim Biophys Acta 2001, 1512:1-14.

21. Kachel K, Asuncion-Punzalan E, London E: Anchoring of tryptophan and tyrosine analogs at the hydrocarbon-polar boundary in model membrane vesicles: parallax analysis of fluorescence quenching induced by nitroxide-labeled phospholipids. Biochemistry 1995, 34:15475-15479.

22. Popova AV, Heyer AG, Hincha DK: Differential destabilization of membranes by tryptophan and phenylalanine during freezing: the roles of lipid composition and membrane fusion. Biochim Biophys Acta 2002, 1561:109-118

23. Popova AV, Hincha DK: Thermotropic phase behavior and headgroup interactions of the nonbilayer lipids phosphatidylethanolamine and monogalactosyldiacylglycerol in the dry state. BMC Biophys 2011, 4:11.

24. MacDonald RC, MacDonald RI, Menco BPM, Takeshita K, Subbarao NK, Hu L: Small-volume extrusion apparatus for preparation of large, unilamellar vesicles. Biochim Biophys Acta 1991, 1061:297-303.

25. Hincha DK, Zuther E, Hellwege EM, Heyer AG: Specific effects of fructo- and gluco-oligosaccharides in the preservation of liposomes during drying. Glycobiology 2002, 12:103-110.
26. Popova AV, Hincha DK: Intermolecular interactions in dry and rehydrated pure and mixed bilayers of phosphatidylcholine and digalactosyldiacylglycerol: a Fourier-transform infrared spectroscopy study. Biophys J 2003, 85:1682-1690.

27. Cacela C, Hincha DK: Low amounts of sucrose are sufficient to depress the phase transition temperature of dry phosphatidylcholine, but not for lyoprotection of liposomes. Biophys J 2006, 90:2831-2842.

28. Lewis RNAH, McElhaney RN: The structure and organization of phospholipid bilayers as revealed by infrared spectroscopy. Chem Phys Lipids 1998, 96:9-21.

29. Mantsch HH, McElhaney RN: Phospholipid phase transitions in model and biological membranes as studied by infrared spectroscopy. Chem Phys Lipids 1991, 57:213-226.

30. Jeffrey GJ: Hydrogen bonds and molecular organization. Food Chem 1997, 56:241-246.

31. Popova AV, Hincha DK: Effects of cholesterol on dry bilayers: interactions between phosphatidylcholine unsaturation and glycolopid or free sugar. Biophys J 2007, 93:1204-1214

32. Blume A, Hübner W, Messner G: Fourier transform infrared spectroscopy of ${ }^{13} \mathrm{C}=$ O-labeled phospholipids. Hydrogen bonding to carbonyl groups. Biochemistry 1988, 27:8239-8249.

33. Lewis RNAH, McElhaney RN: Fourier transform infrared spectroscopy in the study of hydrated lipids and lipid bilayer membranes. In Infrared spectroscopy of biomolecules. Edited by Mantsch HH, Chapman D. New York: Wiley-Liss; 1996:159-202.

34. Wong PTT, Mantsch HH: High-pressure infrared spectroscopic evidence of water binding sites in 1,2-diacyl phospholipids. Chem Phys Lipids 1988, 46:213-224.

35. Hincha DK, Popova AV, Cacela C: Effects of sugars on the stability of lipid membranes during drying. In Advances in planar lipid bilayers and liposomes. vol. 3. Edited by Leitmannova Liu A. Amsterdam: Elsevier; 2006:189-217.

36. Lewis RNAH, McElhaney RN: Calorimetric and spectroscopic studies of the polymorphic phase behavior of a homologous series of $n$-saturated 1,2-diacyl phosphatidylethanolamines. Biophys J 1993, 64:1081-1096.

37. Crowe JH, Crowe LM, Carpenter JF, Rudolph AS, Aurell Wistrom C, Spargo BJ, Anchordoguy TJ: Interaction of sugars with membranes. Biochim Biophys Acta 1988, 947:367-384.

38. Akutsu H: Direct determination by Raman scattering of the conformation of the choline group in phospholipid bilayers. Biochemistry 1981, 20:7359-7366

39. Cacela C, Hincha DK: Monosaccharide composition, chain length and linkage type influence the interactions of oligosaccharides with dry phosphatidylcholine membranes. Biochim Biophys Acta 2006, 1758:680-691.

40. Frias MA, Winik B, Franzoni MB, Levstein PR, Nicastro A, Gennaro AM, Diaz SB, Disalvo EA: Lysophosphatidylcholine-arbutin complexes form bilayerlike structures. Biochim Biophys Acta 2008, 1778:1259-1266.

41. Wolkers WF, Oliver AE, Tablin F, Crowe JH: A Fourier-transform infrared spectroscopy study of sugar glasses. Carbohydr Res 2004, 339:1077-1085.

42. Popova AV, Hincha DK: Specific interactions of tryptophan with phosphatidylcholine and digalactosyldiacylglycerol in pure and mixed bilayers in the dry and hydrated state. Chem Phys Lipids 2004, 132:171-184.

43. Smith AL: Applied infrared spectroscopy. In Chemical analysis. vol. 54. Edited by Elving PJ, Winefordner JD. New York: John Wiley; 1979:286-314.

44. Crowe JH, Oliver AE, Hoekstra FA, Crowe LM: Stabilization of dry membranes by mixtures of hydroxyethyl starch and glucose: the role of vitrification. Cryobiology 1997, 35:20-30.

45. Popova AV, Hincha DK: Effects of the sugar headgroup of a glycoglycerolipid on the phase behavior of phospholipid model membranes in the dry state. Glycobiology 2005, 15:1150-1155.

46. Pohle W, Selle C: Fourier-transform infrared spectroscopic evidence for a novel lyotropic phase transition occurring in dioleoylphosphatidylethanolamine. Chem Phys Lipids 1996, 82:191-198.

47. Hübner W, Blume A: Interactions at the lipid-water interface. Chem Phys Lipids 1998, 96:99-123.

48. Pohle W, Selle C, Fritzsche H, Bohl M: Comparative FTIR spectroscopic study upon the hydration of lecithins and cephalins. J Mol Struct 1997, 408/409:273-277. 
49. Seddon JM, Cevc G, Kaye RD, Marsh D: X-ray diffraction study of the polymorphism of hydrated diacyl- and dialkylphosphatidylethanolamines. Biochemistry 1984, 24:2634-2644.

50. de Kruijff B: Polymorphic regulation of membrane lipid composition Nature 1987, 329:587-588.

51. Tilcock CPS: Lipid polymorphism. Chem Phys Lipids 1986, 40:109-125.

52. Gaede HC, Yau WM, Gawrisch K: Electrostatic contributions to indole-lipid interactions. J Phys Chem B 2005, 109:13014-13023.

53. Grossfield A, Woolf TB: Interaction of tryptophan analogs with POPC lipid bilayers investigated by molecular dynamics calculations. Langmuir 2002, 18:198-210.

54. MacCallum JL, Bennet WFD, Tieleman DP: Distribution of amino acids in a bilayer from computer simulations. Biophys J 2008, 94:3393-3404.

55. Norman KE, Nymeyer $\mathrm{H}$ : Indole localization in lipid membranes revealed by molecular simulation. Biophys J 2006, 91:2046-2054.

56. Persson S, Killian JA, Lindblom G: Molecular ordering of interfacially localized tryptophan analogs in ester- and ether-lipid bilayers studied by ${ }^{2} \mathrm{H}-\mathrm{NMR}$. Biophys J 1998, 75:1365-1371.

57. Petersen FNR, Jensen MO, Nielsen CH: Interfacial tryptophan residues: a role for the cation- $\pi$ effect. Biophys J 2005, 89:3985-3996.

58. Yau W-M, Wimley WC, Gawrisch K, White SH: The preference of tryptophan for membrane interfaces. Biochemistry 1998, 37:14713-14718.

59. Vamparys L, Gautier R, Vanni S, Bennet WFD, Tieleman DP, Antonny B, Etchebest C, Fuchs PFJ: Conical lipids in flat bilayers induce packing defects similar to that induced by positive curvature. Biophys J 2013, 104:585-593.

60. Ollila F, Halling K, Vuorela P, Vuorela H, Slotte JP: Characterization of flavonoid-biomembrane interactions. Arch Biochem Biophys 2002, 399:103-108.

61. Scheidt HA, Pampel A, Nissler L, Gebhardt R, Huster D: Investigation of the membrane localization and distribution of flavonoids by high-resolution magic angle spinning NMR spectroscopy. Biochim Biophys Acta 2004, 1663:97-107.

62. Sun $Y$, Hung $W-C$, Chen F-U, Lee C-C, Huang HW: Interaction of tea catechin (-)-epigallocatechin gallate with lipid bilayers. Biophys J 2009, 96:1026-1035

63. Tamba Y, Ohba S, Kubota M, Yoshioka H, Yoshioka H, Yamazaki M: Single GUV method reveals interaction of tea catechin (-)-epigallocatechin gallate with lipid membranes. Biophys J 2007, 92:3178-3194.

doi:10.1186/2046-1682-6-9

Cite this article as: Popova and Hincha: Interactions of the amphiphiles arbutin and tryptophan with phosphatidylcholine and phosphatidylethanolamine bilayers in the dry state. BMC Biophysics 2013 6:9.

\section{Submit your next manuscript to BioMed Central and take full advantage of:}

- Convenient online submission

- Thorough peer review

- No space constraints or color figure charges

- Immediate publication on acceptance

- Inclusion in PubMed, CAS, Scopus and Google Scholar

- Research which is freely available for redistribution 